\title{
miR-329 regulates the sensitivity of 5-FU in chemotherapy of colorectal cancer by targeting E2F1
}

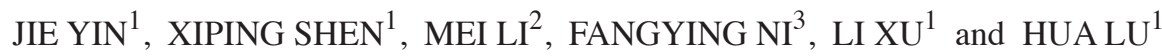 \\ ${ }^{1}$ Department of Anorectal Surgery, The First People's Hospital of Wujiang District, Suzhou, Jiangsu 215200; \\ ${ }^{2}$ Department of Anorectal Surgery, The Second Affiliated Hospital of Hunan University of Chinese Medicine, \\ Changsha, Hunan 410000; ${ }^{3}$ Scientific Education Section, The First People's Hospital of Wujiang District, \\ Suzhou, Jiangsu 215200, P.R. China
}

Received January 12, 2018; Accepted June 25, 2018

DOI: $10.3892 / \mathrm{ol} .2018 .9121$

\begin{abstract}
Colorectal cancer (CRC) is a common digestive system malignancy with high morbidity and mortality. Accumulating studies have shown that miRNAs play a critical role in the progression of $\mathrm{CRC}$. Here, we explored the effect of miR-329 and its target gene on the sensitivity of 5-fluorouracil (5-FU) in the chemotherapy of CRC. RT-qPCR was utilized to determine the expression of miR-329 in cancer tissues, adjacent tissues and cells. CCK- 8 and Transwell assays were introduced to detect the role of miR-329 overexpression in cell viability and invasion. Luciferase reporter assay was performed to verify that E2F1 was a direct target of miR-329. Protein expression of E2F1 was accessed by western blot analysis. The expression level of miR-329 was decreased in CRC tissues and tumor tissues at stage III+IV with lymph node metastasis, and the patients' total survival time was positively associated with the expression of miR-329. Overexpression of miR-329 significantly attenuated the viability and invasiveness of tumor cells. The viability of drug-resistant cells was markedly higher than that of non-resistant cells under the same dose of 5-FU treatment. The expression of miR-329 in tumor cells was negatively associated with drug sensitivity. Luciferase reporter assay showed that E2F1 was the direct target of miR-329. Besides, the expression of E2F1 protein in drug-resistant cells was remarkably higher than that in the non-resistant cells, while the overexpression of miR-329 significantly decreased the expression of E2F1 protein. E2F1 overexpression increased cell viability, but overexpression of both E2F1 and miR-329 in turn decreased cell viability. miR-329 expression is reduced in $\mathrm{CRC}$, and overexpression of miR-329 promotes the sensitivity of 5-FU in the chemotherapy of CRC by degrading the target gene E2F1.
\end{abstract}

Correspondence to: Dr Hua Lu, Department of Anorectal Surgery, The First People's Hospital of Wujiang District, 169 Gongyuan Road, Songling Town, Wujiang, Suzhou, Jiangsu 215200, P.R. China E-mail:1kjxlh@sina.com

Key words: colorectal cancer, miR-329, 5-FU, E2F1

\section{Introduction}

Colorectal cancer (CRC) is one of the most dangerous malignancies in the world. In recent years, the morbidity and mortality of CRC showed an upward trend in China (1). The global cancer statistics in 2011 showed that the incidence of CRC was the third of all malignant tumors in males and the second of all malignant tumors in females, while the mortality of CRC ranked third and fourth of all malignant tumors in females and males (2). It has been reported that $70 \%$ of CRC is associated with somatic mutation and epigenetic variation (3). Therefore, the exploration of relevant regulators will provide theoretical basis and further research directions for the early diagnosis and comprehensive treatment of CRC in the future.

MicroRNAs (miRNAs) are a group of long small non-coding RNAs with 19-22 nucleotide. They are involved in the regulation of many important cellular processes, such as differentiation, cycle regulation, cell stress and apoptosis. Approximately $30 \%$ of human genes are regulated by miRNAs (4). It is reported that about half of the miRNAencoding genes are located at the fragile site related to tumorigenesis, which are easily deleted, amplified or mutated in cancer cells (5). miR-329 is located at 14q32.31, and previous studies have shown that the expression of miR-329 functions a lot in hippocampal neuronal activity-dependent dendritic growth (6). Decreased expression of miR-329 is also observed in glioma cells and tumor tissues (7). However, the relationship between miR-329 and CRC has not been reported till now. In this study, we explored the impact of miR-329 on CRC, which provides the basis for further study on the mechanism of miR-329 and a potential target for the diagnosis and treatment of CRC.

5-Fluorouracil (5-FU) is a first-line chemotherapy drug for the treatment of CRC. It inhibits the activity of pyrimidine nucleotide rate-limiting enzyme-thymidylate synthase and affects the biosynthesis of deoxythymidylate, thereby suppressing tumor cell proliferation $(8,9)$. However, large doses of drugs make the tumor cells prone to drug resistance (10). Our study focused on how to improve the effect of 5-FU.

E2F family included 8 family members (E2F1-8), which are important regulatory factors in cellular processes. E2Fs encode transcriptional regulators and exert essential roles in 

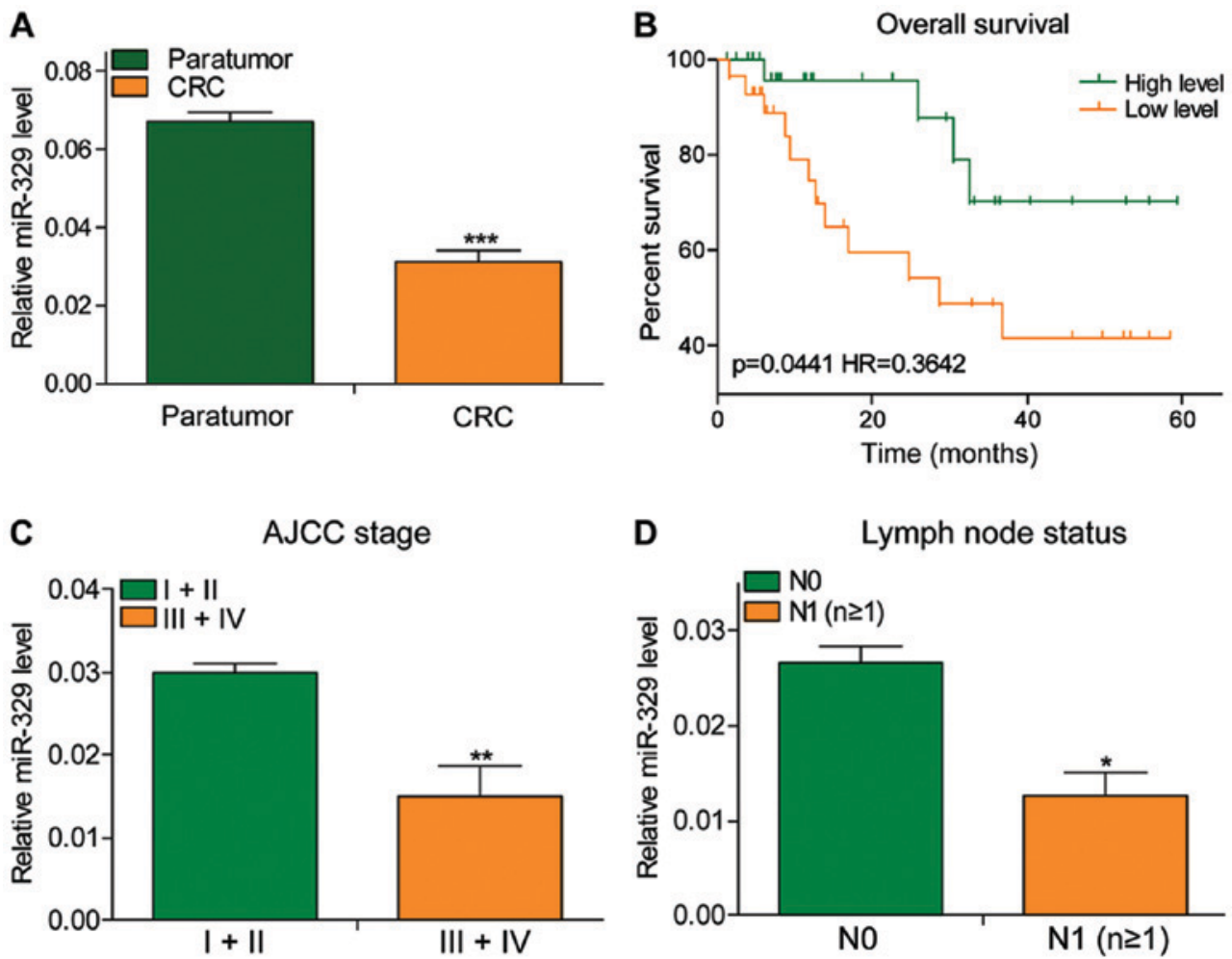

Figure 1. miR-329 expression decreased in CRC. (A) The expression of miR-329 in 56 cases of CRC tissues was significantly lower than that in adjacent tissues. (B) The overall survival of the miR-329-overexpressed group was significantly greater than that of the low-expression group. (C) The expression of miR-329 in stage III+IV CRC tissues was lower than that in stage I+II. (D) miR-329 was less expressed in lymph node metastatic CRC tissues than in cancer tissues with non-metastatic lymph nodes. CRC, colorectal cancer. ${ }^{*} \mathrm{P}<0.05 ;{ }^{* * *} \mathrm{P}<0.01 ;{ }^{* * *} \mathrm{P}<0.001$.

the G1/S transition of mammalian cell (11). E2F1 has both cancer-promoting and tumor-suppressive activities. On the one hand, E2F1 acts as a target gene activator to induce cell transition from the G0 to the S phase. On the other hand, it induces apoptosis as a target gene inhibitor. It has been reported that miRNA-34 targets E2F-related pathways to induce apoptosis in cancer cells (12). However, the role of E2F1 and miR-329 in CRC chemotherapy sensitivity have not been reported. Therefore, the regulation of E2F1 by miR-329 on the chemotherapeutic effect of 5-FU is particularly significant.

\section{Materials and methods}

miR-329 expression analysis. We used RT-qPCR to access the expression of miR-329 in CRC tissues as well as their corresponding adjacent tissues from 56 patients (aged $65.2 \pm 69.5$ and ranging berween 47-81 years). A total of 37 male patients and 19 female patients were diagnosed with colorectal cancer at the First People's Hospital of Wujiang District (Suzhou, China) between June 2015 and September 2017. Among these patients, 35 were graded with stage I+II while another 21 were graded with stage III+IV. Additionally, the expression level of miR-329 in drug-resistant and non-resistant tumor cells treated with or without 5-FU were also detected. This study was approved by the Ethics Committee of the First People's Hospital of Wujiang District (Suzhou, China).

Cell culture. The HCT116 and SW480 cells were cultured in Dulbecco's modified Eagle's medium (DMEM) containing $10 \%$ fetal bovine serum (FBS) and 1,000 U/ml penicillin.
The cells were maintained at $37^{\circ} \mathrm{C}$ with $5 \% \mathrm{CO}_{2}$. The cells were digested and seeded into 6 -well plates $\left(2 \times 10^{5} /\right.$ well) and cultured for $24 \mathrm{~h}$. Transfection of miR-329 mimic was performed in accordance with the instructions.

CCK-8 assays. The cells in logarithmic growth phase were digested by trypsin and then inoculated into 96 -well plates $(100 \mu \mathrm{l})$ at a density of $3 \times 10^{4} / \mathrm{ml}$. After $24 \mathrm{~h}$ incubation, the original medium was replaced by a mixture containing $10 \%$ CCK-8 working solution and then incubated at $37^{\circ} \mathrm{C}$ with $5 \%$ $\mathrm{CO}_{2}$ for $4 \mathrm{~h}$. The absorbance value at $450 \mathrm{~nm}$ was read with a microplate reader (Bio-Rad, Hercules, CA, USA).

Transwell assays. Cells transfected with or without miR-329 mimic were seeded onto pretreated Matrigel. The wells with a pore size of $8 \mu \mathrm{m}$ were placed in a 24-well plate, and $700 \mu \mathrm{l}$ of RPMI-1640 medium containing 15\% FBS was added to the lower chamber, $200 \mu \mathrm{l}$ starved cells were added to the upper chamber at a density of $2 \times 10^{5} / \mathrm{ml}$. Forty-eight hours later, the supernatant fluid was removed, and the cells were fixed with $4 \%$ paraformaldehyde for $20 \mathrm{~min}$ followed by stained with $0.1 \%$ crystal violet for $20 \mathrm{~min}$. After removing the cells stranded in chambers, the cells that passed through the chamber were observed under an optical microscope (BX-42; Olympus, Tokyo, Japan) (x100 magnification) and photographed to calculate the number.

Luciferase reporter gene assays. Cells were cultured in 24-well plates and transfected with 200 ng luciferase reporter plasmids (QIAGEN, Duesseldorf, Germany), 50 ng Renilla plasmids 
A

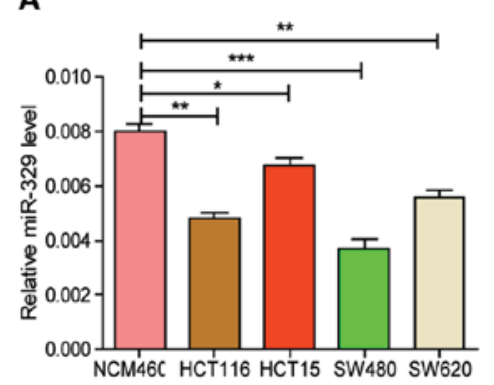

D

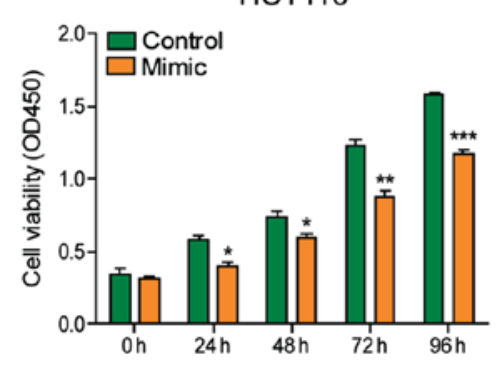

F

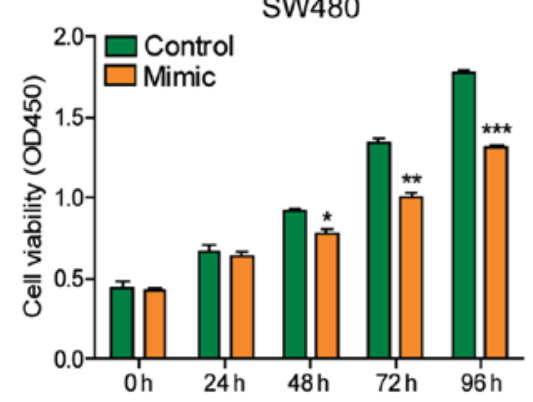

B

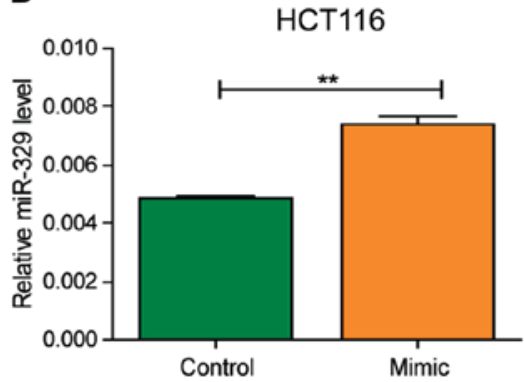

E

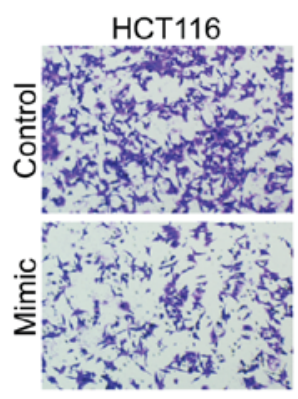

G

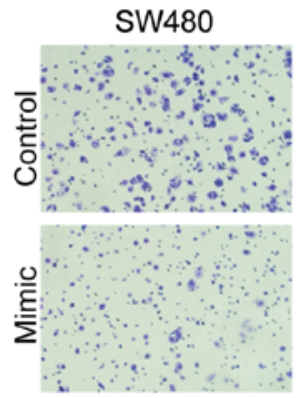

C
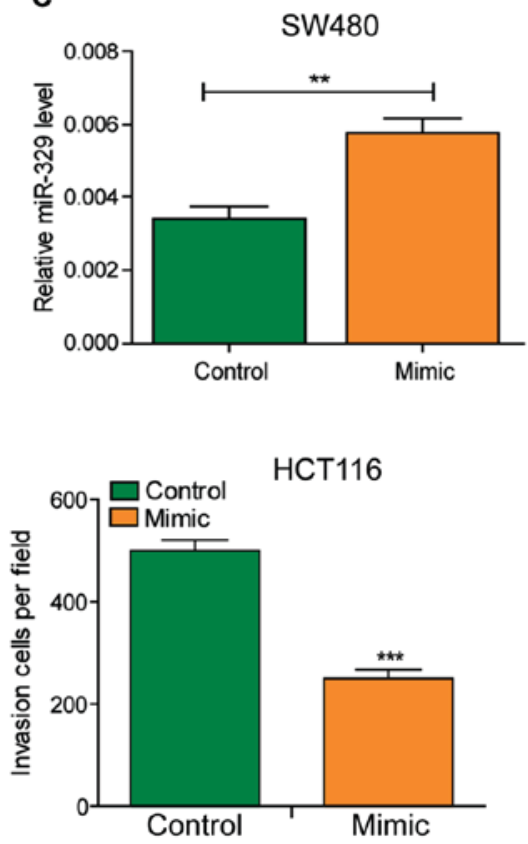

SW480

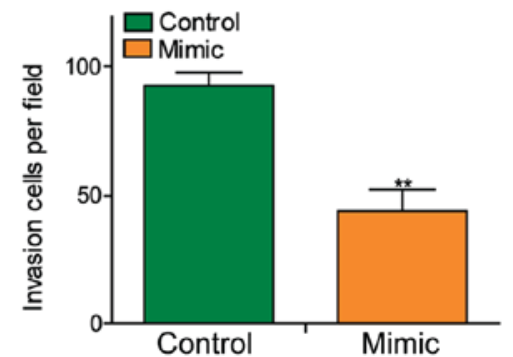

Figure 2. miR-329 inhibited the viability and invasion of CRC cells. (A) Among all the colorectal normal cell line (NCM460) and the CRC cell lines (HCT116, HCT15, SW480, SW620), miR-329 showed a significant decreased expression in HCT116 and SW480. (B and C) miR-329 expression was significantly increased after transfection of miR-329 mimic in HCT116 cells and SW480 cells. (D and E) Overexpression of miR-329 in HCT116 cells significantly reduced cell invasion. (F and G) Overexpression of miR-329 in SW480 cells resulted in a significant decrease in cell viability and invasion ability. CRC, colorectal cancer. ${ }^{*} \mathrm{P}<0.05 ;{ }^{* *} \mathrm{P}<0.01 ;{ }^{* * *} \mathrm{P}<0.001$.

or $60 \mathrm{ng}$ target gene plasmids based on different expression levels, respectively. Six hours after transfection, Wnt3a or $\mathrm{LiCl}$ was added to stimulate for additional $24-48 \mathrm{~h}$, after which the cells were lysed and harvested by $120 \mu \mathrm{l}$ of PLB per well. The cells were then centrifuged at $1,750 \mathrm{x}$ g for $3 \mathrm{~min}$, and $20 \mu \mathrm{l}$ of cell lysate supernatant in each well were measured to achieve the Luciferase and Renilla fluorescence.

Western blot analysis. Protein samples were separated by polyacrylamide gels with different concentration at $80 \mathrm{~V}$ for $2 \mathrm{~h}$ and then transferred to polyvinylidene fluoride (PVDF) membrane. After blocked in $5 \%$ defatted milk at $37^{\circ} \mathrm{C}$ for $1 \mathrm{~h}$, the membranes were incubated with specific primary antibodies at $4^{\circ} \mathrm{C}$ overnight. Rabbit polyclonal caspase-3 antibody (dilution, 1:500; cat. no. ab13847), rabbit polyclonal PARP1 antibody (dilution, 1/500; cat. no. ab32138) and rabbit monoclonal Bax antibody (dilution, 1/500; cat. no. ab32503) were all purchased from Abcam (Cambridge, MA, USA). The membranes were washed with $1 \%$ Tris-buffered saline-Tween-20 (TBST) and incubated with secondary goat anti-rabbit (HRP) IgG antibody (dilution, 1/2,000; cat. no. ab6721) at room temperature for at least $1 \mathrm{~h}$. After that, these protein bands were subjected to enhanced chemiluminescence (ECL) and then imaged.

Statistical analysis. We used Statistical Product and Service Solutions (SPSS) 22.0 software (IBM, Armonk, NY, USA) for statistical analysis. Chi-square test was used to analyze clinical classification data. Kaplan-Meier survival curves were introduced for survival analysis. Independent-samples t-tests between two groups was performed for statistical test. Comparison between multiple groups was done using One-way ANOVA test followed by post hoc test (Least Significant Difference). $\mathrm{P}<0.05$ was considered to indicate a statistically significant difference.

\section{Results}

miR-329 expression decreased in CRC. The expression of miR-329 showed a significant decrease in CRC tissues, especially the tumor tissues at stage III+IV with lymph node 
A
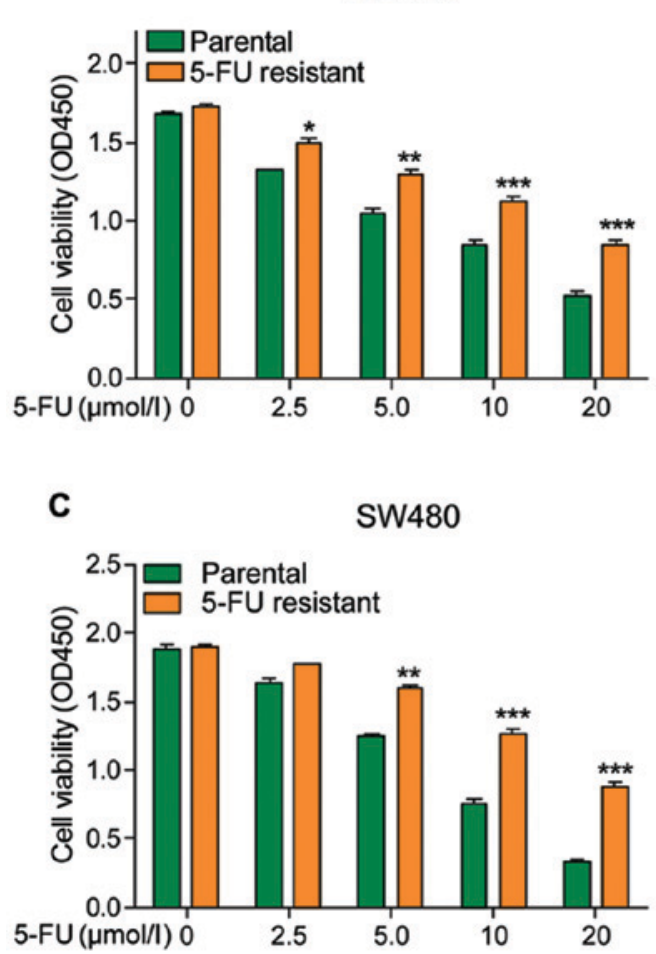

B

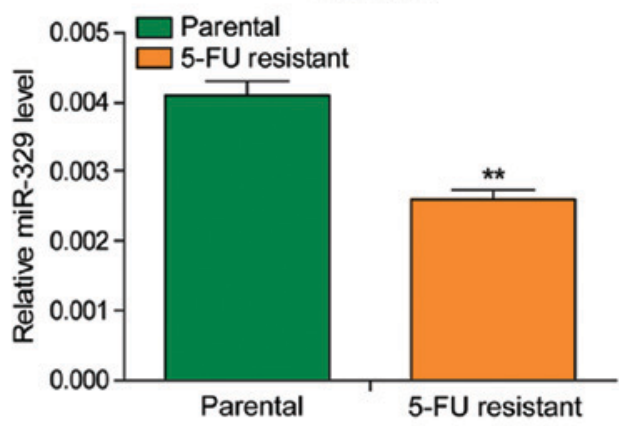

D

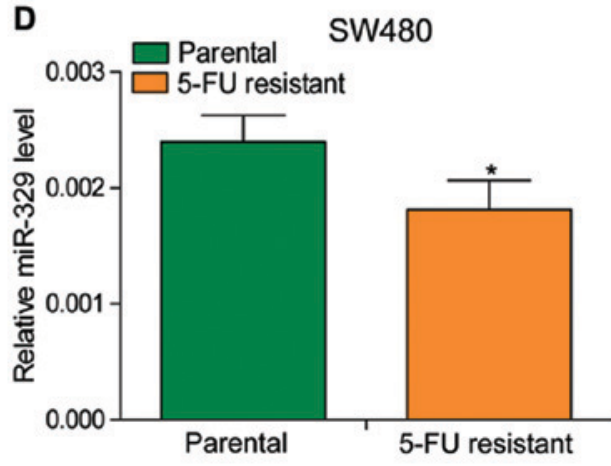

Figure 3. miR-329 expression level was positively associated with the sensitivity of cancer cells to 5-FU. (A) In HCT116 cells and drug-resistant HCT116 cells treated with different concentrations of 5-FU, cell viability decreased with the increase of 5-FU concentration, and the viability of drug-resistant HCT116 cells was higher than that of non-drug-resistant cells. (B) The expression of miR-329 in drug-resistant HCT116 cells was significantly lower than in nonresistant cells. (C) Treatment with different concentrations of 5-FU in SW480 cells and drug-resistant SW480 cells showed that cell viability was decreased with increasing concentration of 5-FU, and the viability of SW480 cells was higher than that of non-drug-resistant cells. (D) The expression of miR-329 in drug-resistant cells was significantly lower than that in non-resistant cells. 5-FU, 5-fluorouracil. ${ }^{*} \mathrm{P}<0.05 ;{ }^{* *} \mathrm{P}<0.01 ;{ }^{* * *} \mathrm{P}<0.001$.

metastasis (Fig. 1A, C and D). The patients' total survival time was positively associated with the expression of miR-329 (Fig. 1B; $\mathrm{P}=0.0441, \mathrm{HR}=0.3642$ ).

miR-329 inhibited the viability and invasion of CRC cells. After initially identifying the expression of miR-329 in CRC tissues, we detected the expression level of miR-329 in cells with RT-qPCR (Fig. 2A). The results showed that the miR-329 level in tumor cell lines was significantly lower than that in normal cell lines. Subsequently, we exogenously increased the level of miR-329 in cells by transfecting miR-329 mimic into HCT116 and SW480 cells (Fig. 2B and C). CCK-8 and Transwell assays revealed that the viability and invasion ability of cells were significantly decreased after miR-329 mimic transfection (Fig. 2D-G).

miR-329 expression level was positively associated with the sensitivity of cancer cells to 5-FU. To determine the effects of 5-FU, different concentrations of 5-FU were used to treat the cells. The viability of cells declined in a dose-dependent manner and the viability of drug-resistant cells was significantly higher than that of non-resistant cells under the same concentration of 5-FU treatment (Fig. 3A and C). Besides, the expression of miR-329 was also observed much lower in drug-resistant cells when compared to non-resistant cells (Fig. 3B and D). The above data indicated that 5-FU could inhibit the vitality of cancer cells, and the sensitivity of cancer cells to 5-FU is positively associated with the expression of miR-329.
miR-329 increased the sensitivity of CRC cells to 5-FU by decreasing the expression of E2F1. To further explore the mechanism of miR-329 in CRC, we predicted that E2F1 may be a potential target gene of miR-329 by searching the bioinformatics website (DIANA, miRanda, PicTar) (Fig. 4A). The results of luciferase reporter assay illustrated that miR-329 reduced the relative luciferase activity of wild-type E2F1 gene but had no effect on the luciferase activity of mutant reporter plasmids, indicating that E2F1 was the direct target of miR-329 (Fig. 4B and C). E2F1 expression was significantly higher in drug-resistant cells than that in the non-resistant cells (Fig. 4D). After overexpression of miR-329, E2F1 expression was significantly decreased in cells (Fig. 4E). The results of CCK- 8 assay indicated that cell viability was markedly upregulated by the overexpression of E2F1, while the enhanced expression of miR-329 could partially reverse this effect. The result of this section indicated that E2F1 could reduce the chemotherapy effect on CRC, but the effect would be improved after the upregulation of miR-329 (Fig. 4F and G).

\section{Discussion}

$\mathrm{CRC}$ is one of the most common digestive system malignancies (13). With the progress of molecular biology, cell biology, immunology and other disciplines, people's understanding of CRC has gradually extended to deeper fields. Although chemotherapeutic drugs have been widely used in the treatment of malignant tumors, the survival status of patients with 
A

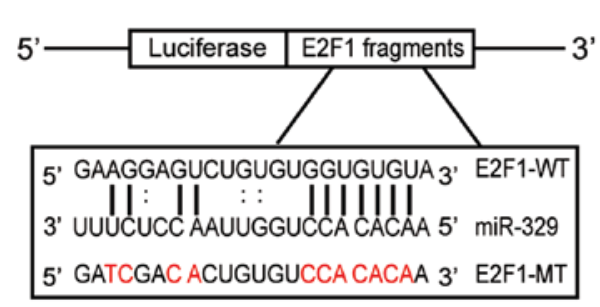

B

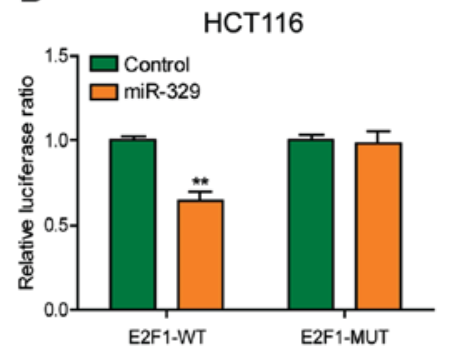

C

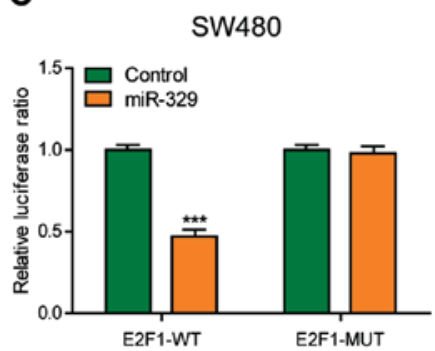

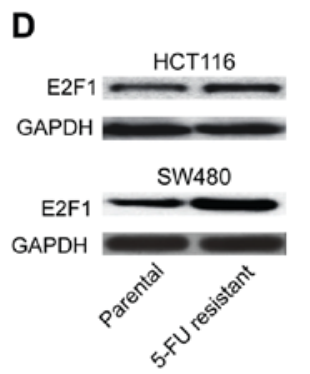

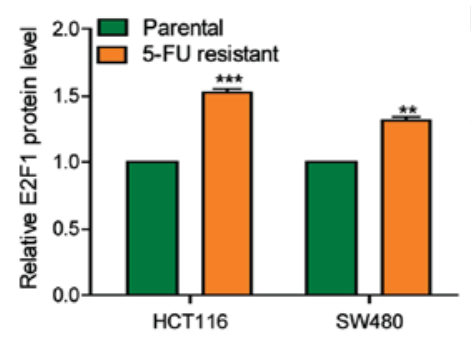

$E$

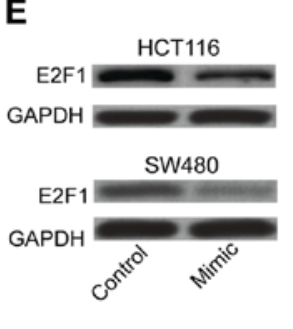

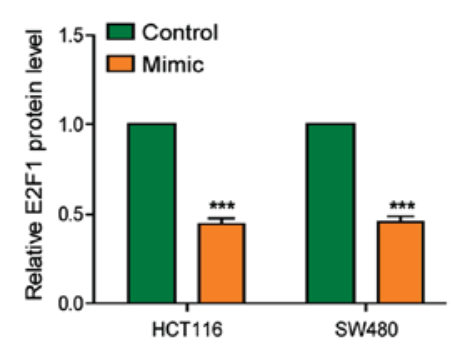
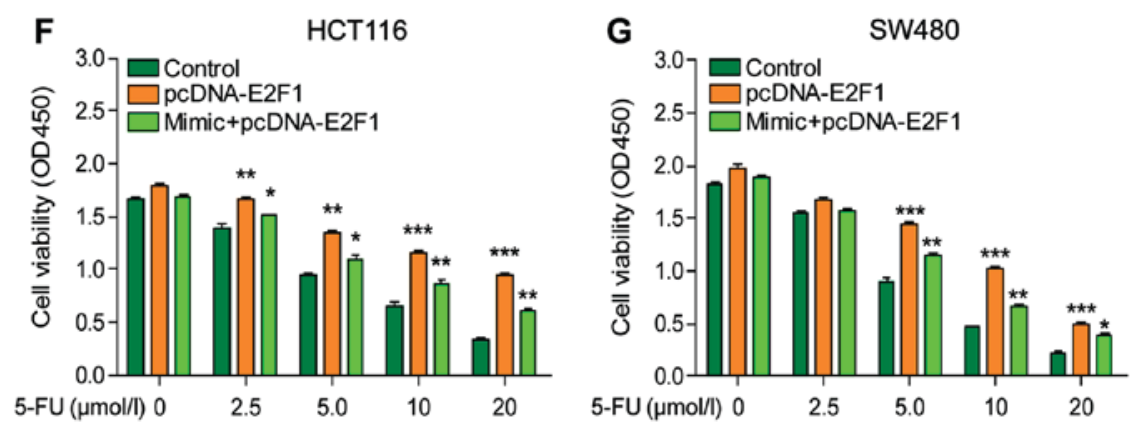

Figure 4. miR-329 enhanced the sensitivity of CRC cells to 5-FU by decreasing the expression of E2F1. (A) The binding site in E2F1 mRNA for miR-329. (B and C) Luciferase reporter assay confirmed the direct binding of E2F1 and miR-329 in HCT116 and SW480 cells. (D) E2F1 expression was significantly higher in drug-resistant cells than that in non-resistant cells. (E) The E2F1 expression was significantly reduced after upregulation of miR-329. (F and G) Overexpression of E2F1 significantly increased cell viability in HCT116 and SW480 cells, while overexpression of both E2F1 and miR-329 partially reversed the cell activity. CRC, colorectal cancer; 5-FU, 5-fluorouracil. ${ }^{*} \mathrm{P}<0.05 ;{ }^{* * *} \mathrm{P}<0.01 ;{ }^{* * * *} \mathrm{P}<0.001$.

tumor metastasis/recurrence remains unsatisfactory due to the drug resistance of tumor cells and their significant differences in drug sensitivity (14). Therefore, the deep exploration of the biological characteristics of CRC will help to further optimize the treatment strategy and improve the efficacy of the chemotherapeutic drugs. Recently, miRNAs have been reported to participate in the development of CRC.

Accumulating evidence indicated that miRNAs may play an extremely important regulatory role in cells. Various proteincoding genes can be regulated by only one single miRNA (15). miRNAs are found to be dysregulated in many diseases, including cancer. The first study confirming that miRNAs are tumor-related is in the research on chronic lymphocytic leukemia (CLL), and the expression level of miR-15a and miR-16a are downregulated or absent in $\sim 68 \%$ of CLL patients as reported (16). Subsequent studies also found that miRNA expression is altered in many other types of tumors, such as gastric cancer, prostate cancer, esophageal cancer and CRC (17). Our study found that the expression level of miR-329 was decreased in CRC. The abnormal expression of miR-329 could significantly reduce the viability and invasion ability of CRC cells.
In addition to its role in CRC pathology, miRNAs may also be involved in affecting the sensitivity of CRC to chemotherapeutic drugs. Lower expression of miR-329 in drug-resistant cells was observed than that in the non-resistant cells. Similar to our conclusion, some studies have found that the upregulation of miR-140 was also related to drug resistance in tumor treatment, which meant that miRNAs also play an indispensable role in CRC chemoresistance (18).

The abnormal expression of E2F1 has different functions in different tumors as reported. Previous studies have shown that the overexpression of $\mathrm{E} 2 \mathrm{~F} 1$ results in abnormal proliferation of cells and promotes tumorigenesis (19). Besides, the E2F1 expression is elevated in a variety of tumors, for example, lung and breast cancer (20). In this study, E2F1 was also observed highly expressed in drug-resistant cells and the overexpression of E2F1 significantly increased the viability of cells. However, these phenomena were partially reversed after the overexpression of miR-329. Moreover, miR-329 reduced the expression of E2F1 via directly targeting its 3'UTR, thereby enhancing the killing effect of 5-FU to CRC cells. 
In conclusion, our data indicated that the expression level of miR-329 was reduced in CRC, and the overexpression of miR-329 promoted the sensitivity of 5-FU in the chemotherapy of CRC by degrading the target gene E2F1. These results may provide a theoretical basis for the gene therapy of CRC and provide an experimental basis for further study of CRC.

\section{Acknowledgements}

Not applicable.

\section{Funding}

No funding was received.

\section{Availability of data and materials}

All data generated or analyzed during this study are included in this published study.

\section{Authors' contributions}

JY and HL were responsible for the design and preparation of the study. XS was responsible for data collection. ML was responsible for data analysis. FN was responsible for data interpretation. LX performed RT-qPCR. All authors have read and approved the final study.

\section{Ethics approval and consent to participate}

This study was approved by the Ethics Committee of The First People's Hospital of Wujiang District (Suzhou, China). Signed written informed consents were obtained from the patients and/or guardians.

\section{Patient consent for publication}

Not applicable.

\section{Competing interests}

The authors declare that they have no competing interests.

\section{References}

1. Chen W, Zheng R, Baade PD, Zhang S, Zeng H, Bray F, Jemal A, Yu XQ and He J: Cancer statistics in China, 2015. CA Cancer J Clin 66: 115-132, 2016.

2. Jemal A, Bray F, Center MM, Ferlay J, Ward E and Forman D: Global cancer statistics. CA Cancer J Clin 61: 69-90, 2011.

3. $\mathrm{Hu} \mathrm{T}, \mathrm{Li} \mathrm{Z}, \mathrm{Gao} \mathrm{CY}$ and Cho $\mathrm{CH}$ : Mechanisms of drug resistance in colon cancer and its therapeutic strategies. World J Gastroenterol 22: 6876-6889, 2016.
4. Rajewsky N: MicroRNA target predictions in animals. Nat Genet 38 (Suppl): S8-S13, 2006.

5. Wijnhoven BP, Michael MZ and Watson DI: MicroRNAs and cancer. Br J Surg 94: 23-30, 2007.

6. Brower JV, Clark PA, Lyon W and Kuo JS: MicroRNAs in cancer: Glioblastoma and glioblastoma cancer stem cells. Neurochem Int 77: 68-77, 2014.

7. Møller HG, Rasmussen AP, Andersen HH, Johnsen KB Henriksen M and Duroux M: A systematic review of microRNA in glioblastoma multiforme: Micro-modulators in the mesenchymal mode of migration and invasion. Mol Neurobiol 47: 131-144, 2013.

8. Yadunandam AK, Yoon JS, Seong YA, Oh CW and Kim GD: Prospective impact of 5-FU in the induction of endoplasmic reticulum stress, modulation of GRP78 expression and autophagy in Sk-Hep1 cells. Int J Oncol 41: 1036-1042, 2012.

9. Deng YH, Pu XX, Huang MJ, Xiao J, Zhou JM, Lin TY and Lin EH: 5-Fluorouracil upregulates the activity of Wnt signaling pathway in CD133-positive colon cancer stem-like cells. Chin J Cancer 29: 810-815, 2010.

10. Hotta T, Takifuji K, Arii K, Yokoyama S, Matsuda K, Higashiguchi T, Tominaga T, Oku Y and Yamaue H: Clinical impact of adjuvant chemotherapy on patients with stage III colorectal cancer: $1-\mathrm{LV} / 5 \mathrm{FU}$ chemotherapy as a modified RPMI regimen is an independent prognostic factor for survival. Anticancer Res 26 (2B): 1425-1432, 2006.

11. Ogawa H, Ishiguro K, Gaubatz S, Livingston DM and Nakatani Y: A complex with chromatin modifiers that occupies E2F- and Myc-responsive genes in G0 cells. Science 296: 1132-1136, 2002.

12. Dong F and Lou D: MicroRNA-34b/c suppresses uveal melanoma cell proliferation and migration through multiple targets. MOL VIS 18: 537-546, 2012.

13. Westphalen CB, Asfaha S, Hayakawa Y, Takemoto Y, Lukin DJ, Nuber AH, Brandtner A, Setlik W, Remotti H, Muley A, et al: Long-lived intestinal tuft cells serve as colon cancer-initiating cells. J Clin Invest 124: 1283-1295, 2014.

14. Tournigand C, André T, Achille E, Lledo G, Flesh M, Mery-Mignard D, Quinaux E, Couteau C, Buyse M, Ganem G, et al: FOLFIRI followed by FOLFOX6 or the reverse sequence in advanced colorectal cancer: A randomized GERCOR study. J Clin Oncol 22: 229-237, 2004.

15. Wurdinger T and Costa FF: Molecular therapy in the microRNA era. Pharmacogenomics J 7: 297-304, 2007.

16. Calin GA, Dumitru CD, Shimizu M, Bichi R, Zupo S, Noch E, Aldler H, Rattan S, Keating M, Rai K, et al: Frequent deletions and down-regulation of micro-RNA genes miR15 and miR16 at 13q14 in chronic lymphocytic leukemia. Proc Natl Acad Sci USA 99: 15524-15529, 2002.

17. Visone R and Croce CM: miRNAs and cancer. Am J Pathol 174: 1131-1138, 2009.

18. Song B, Wang Y, Xi Y, Kudo K, Bruheim S, Botchkina GI, Gavin E, Wan Y, Formentini A, Kornmann M, et al: Mechanism of chemoresistance mediated by miR-140 in human osteosarcoma and colon cancer cells. Oncogene 28: 4065-4074, 2009.

19. Yamasaki L, Bronson R, Williams BO, Dyson NJ, Harlow E and Jacks T: Loss of E2F-1 reduces tumorigenesis and extends the lifespan of Rb1(+/-) mice. Nat Genet 18: 360-364, 1998.

20. Zacharatos P, Kotsinas A, Evangelou K, Karakaidos P, Vassiliou LV, Rezaei N, Kyroudi A, Kittas C, Patsouris E, Papavassiliou AG, et al: Distinct expression patterns of the transcription factor E2F-1 in relation to tumour growth parameters in common human carcinomas. J Pathol 203: 744-753, 2004.

This work is licensed under a Creative Commons Attribution-NonCommercial-NoDerivatives 4.0 International (CC BY-NC-ND 4.0) License. 